\title{
Baicalein, an active component of Scutellaria baicalensis Georgi, induces apoptosis in human colon cancer cells and prevents AOM/DSS-induced colon cancer in mice
}

\author{
DONG HWAN KIM ${ }^{1}$, MOHAMMAD AKBAR HOSSAIN ${ }^{1,2}$, YONG JUNG KANG ${ }^{1}$, JUNG YOON JANG ${ }^{1}$, \\ YU JIN LEE ${ }^{1}$, EUNOK IM ${ }^{1}$, JEONG-HYUN YOON ${ }^{1}$, HYUNG SIK KIM ${ }^{3}$, \\ $\mathrm{HAE} \mathrm{YOUNG} \mathrm{CHUNG}^{1}$ and NAM DEUK KIM ${ }^{1}$
}

\author{
${ }^{1}$ Department of Pharmacy, Molecular Inflammation Research Center for Aging Intervention, Pusan National University, \\ Busan, Republic of Korea; ${ }^{2}$ Department of Pharmacology and Toxicology, Faculty of Pharmacy, \\ Umm Al-Qura University, Makkah, Saudi Arabia; ${ }^{3}$ Division of Toxicology, College of Pharmacy, \\ Sungkyunkwan University, Suwon, Gyeonggi-do, Republic of Korea
}

Received July 9, 2013; Accepted August 12, 2013

DOI: 10.3892/ijo.2013.2086

\begin{abstract}
Flavonoids have been demonstrated to provide health benefits in humans. Baicalein (5,6,7-trihydroxyflavone) is a phenolic flavonoid compound derived mainly from the root of Scutellaria baicalensis Georgi, a medicinal plant traditionally used in oriental medicine. Baicalein is widely used in Korean and Chinese herbal medicines as anti-inflammatory and anticancer therapy. However, the molecular mechanisms of its activity remain poorly understood and warrant further investigation. This study was performed to investigate the anticancer effect of baicalein on HCT116 human colon cancer cells and the tumor preventing capacity of baicalein on colitisassociated cancer in mice. In in vivo experiments, we induced colon tumors in mice by azoxymethane (AOM) and dextran sulfate sodium (DSS) and evaluated the effects of baicalein on tumor growth. Baicalein treatment on HCT116 cells resulted in a concentration-dependent inhibition of cell growth and induction of apoptotic cell death. The induction of apoptosis was determined by morphological changes and cleavage of poly(ADP-ribose) polymerase. Baicalein also suppressed the activation of NF- $\kappa \mathrm{B}$ through PPAR $\gamma$ activation. These results indicate that the anti-inflammatory effects of baicalein may be mediated through PPAR $\gamma$ activation. Finally, administration with baicalein significantly decreased the incidence of tumor formation with inflammation. Our findings suggest
\end{abstract}

Correspondence to: Dr Nam Deuk Kim, Department of Pharmacy, College of Pharmacy, Pusan National University, 63 Beon-gil 2, Busandaehag-ro, Geumjeong-gu, Busan 609-735, Republic of Korea E-mail: nadkim@pusan.ac.kr

Key words: baicalein, colon cancer, apoptosis, azoxymethane/ dextran sulfate sodium model that baicalein is one of the candidates for the prevention of inflammation-associated colon carcinogenesis.

\section{Introduction}

Colorectal cancer (CRC) is a malignant neoplasm arising from the lining of the large intestine (colon and rectum). $\mathrm{CRC}$ is the third most common malignancy and one of the major causes of cancer-related death in the United States (1). Colitis-associated cancer (CAC) is the type of colon cancer which is preceded by clinically detectable inflammatory bowel disease (IBD), such as Crohn's disease (CD) or ulcerative colitis (UC) (2). IBD results from the inappropriate and ongoing activation of the mucosal immune system, and this is driven by the presence of normal luminal flora. As many as 1.4 million persons in the United States and 2.2 million persons in Europe suffer from these diseases (3). The incidence of IBD in Korea has increased significantly over the past few decades. In case of prevalence for UC in South Korea, it was quadrupled from 7.57/10 individuals in 1997 to $30.9 / 10^{5}$ individuals in 2005. Adjusted prevalence rates of $\mathrm{CD}$ and UC per $10^{5}$ individuals were 11.2 and 30.9 , respectively (4). In case of incidence of IBD in Japan, the number of patient is increased with time. The age-standardized prevalence of UC in Japan in 2005 was $63.6 / 10^{5}$ individuals, and that of $C D$ was $21.2 / 10^{5}$ individuals. Incidence rate of $\mathrm{UC}$ and $\mathrm{CD}$ are higher than South Korea. The prevalence of inflammatory bowel diseases is much lower in Asian countries, including Japan and Korea, than in Western countries, but it is rapidly increasing (5). Chronic IBD such as UC and CD cause colitis-associated colon cancer.

Peroxisome proliferator-activated receptors $\gamma$ (PPAR $\gamma$ ), which belongs to the nuclear receptor superfamily, is a ligand-activated transcription factor that forms heterodimer with retinoic X receptor (RXR) and stimulates expression of target genes. It is expressed in various tissues and cell types, including those from the pancreas, liver, kidney, adipose tissue 
and colon (6). Further, several lines of evidence indicate that PPAR $\gamma$ plays an important role in regulating inflammatory responses in the intestine (7). PPAR $\gamma$ and its activators are known as important modulators having anti-inflammatory properties that can modulate nuclear factor- $\mathrm{\kappa B}(\mathrm{NF}-\kappa \mathrm{B})$ activation. Rosiglitazone, PPAR $\gamma$ activator, was tested in clinical trials and was found to be effective in the treatment of UC (8). Dietary punicic acid ameliorates intestinal inflammation by activation of PPAR $\gamma$ in mice (9). Previous studies have provided evidence that PPAR $\gamma$ can inhibit inflammatory gene expression by several mechanisms, including competition for a limiting pool of co-activators, direct interaction with NF- $\mathrm{KB}$, p65 and p50 subunits, modulation of p38 mitogen-activated protein kinase (MAPK) activity, and partitioning the co-repressor B cell lymphoma-6 (BCL-6) (10). So use of PPAR $\gamma$ agonists could be beneficial in inflammation related diseases such as IBD.

Baicalein (5,6,7-trihydroxyflavone, Fig. 1) one of four major flavonoids found in Scutellaria baicalensis Georgi, is widely used in Chinese herbal medicine and has been used in various inflammatory diseases and ischemia (11). Treatment with baicalein has been reported to attenuate endothelium intimal hyperplasia by inhibiting inflammatory signaling pathways involving extracellular signal-regulated kinase (ERK), Akt and NF-kB activities in vascular smooth muscle cells (12). Baicalein attenuates the radiation-induced inflammation process in mouse kidney by modulation of NF- $\mathrm{KB}$ and Forkhead family of transcription factors (FOXOs) (13). It has been shown that baicalein has an inhibitory effect on colorectal cancer (14). Baicalein also enacts anticancer activity by inhibiting platelet-type 12-lipoxygenase (12-LOX), which has been shown to regulate growth, metastasis and angiogenesis in prostate cancer (15). The above accumulating evidence demonstrates that biacalein possesses potent anticancer and anti-inflammatory activities.

However, knowledge of the protective role of baicalein in colon cancer on the expression and regulation of apoptosis and inflammatory mediators associated with colon cancer is still unknown. Hence, in the present study we aimed to evaluate the chemopreventive effects of baicalein on human colon cancer cells and AOM/DSS-induced colitis-associated colon cancer in mice. We demonstrate that baicalein is a potent chemopreventive and anti-inflammatory agent that may act through the activation of PPAR $\gamma$ to inhibit NF- $\kappa B$ activation in colon cancer.

\section{Materials and methods}

Chemicals. Baicalein was purchased from Sigma-Aldrich Co. (St. Louis, MO). Baicalein was freshly prepared before each experiment and was solubilized with dimethylsulfoxide (DMSO). The final concentration of DMSO in the medium was less than $0.1 \%(\mathrm{vol} / \mathrm{vol})$ in the treatment range $(25-100 \mu \mathrm{M})$ and showed no influence on cell growth (data not shown).

Cell culture and cell viability assay. The human colorectal cancer HCT116 cells were cultured in RPMI-1640 (HyClone, Logan, UT) supplemented with $10 \%$ fetal bovine serum (FBS, HyClone), $2 \mathrm{mM}$ glutamine (Sigma-Aldrich), $100 \mathrm{U} / \mathrm{ml}$ penicillin (HyClone) and $100 \mu \mathrm{g} / \mathrm{ml}$ streptomycin (HyClone) at $37^{\circ} \mathrm{C}$ in a humidified $5 \% \mathrm{CO}_{2}$. Cell viability was determined

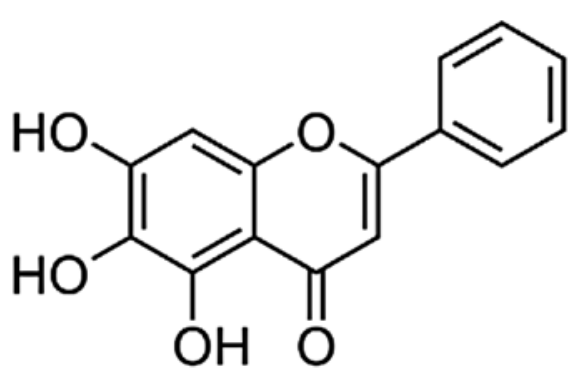

Figure 1. Structure of baicalein (5,6,7-trihydroxyflavone).

by MTT assay. For the MTT assay, HCT116 cells were seeded in a 24 -well culture plate at a density of $4 \times 10^{4}$ cells/well, cultured for $24 \mathrm{~h}$ in the growth media and then treated with or without baicalein for the indicated concentrations. The cells were incubated with $0.5 \mathrm{mg} / \mathrm{ml}$ MTT [3-(4,5-dimethylthiazol2-yl)-2,5-diphenyltetrazolium bromide] (Sigma-Aldrich) at $37^{\circ} \mathrm{C}$ for $2 \mathrm{~h}$. The formazan granules generated by the live cells were dissolved in DMSO and the absorbance at $540 \mathrm{~nm}$ was monitored by using a multi-well reader.

Western blot analysis. The cells were treated under the appropriate conditions, harvested, washed with cold PBS and then lysed in lysis buffer [40 mM Tris ( $\mathrm{pH} 8.0), 120 \mathrm{mM} \mathrm{NaCl}$, $0.5 \% \mathrm{NP}-40,0.1 \mathrm{mM}$ sodium orthovanadate, $2 \mu \mathrm{g} / \mathrm{ml}$ aprotinin, $2 \mu \mathrm{g} / \mathrm{ml}$ leupeptin and $100 \mu \mathrm{g} / \mathrm{ml}$ phenymethylsulfonyl fluoride (PMSF)]. The supernatant was collected and protein concentrations were measured (Pierce, Rockford, IL). Protein extracts were denatured by boiling at $100^{\circ} \mathrm{C}$ for $5 \mathrm{~min}$ in sample buffer $(0.5 \mathrm{M}$ Tris-HCl, $\mathrm{pH} 6.8,4 \% \mathrm{SDS}, 20 \%$ glycerol, $0.1 \%$ bromophenol blue, $10 \% \beta$-mercaptoethanol). Equal amount of the total proteins were subjected to 6-15\% SDS-PAGE and transferred to PVDF. The membranes were blocked with $5 \%$ non-fat dry milk in Tris-buffered saline with Tween-20 buffer (TBS-T) $(20 \mathrm{mM}$ Tris, $100 \mathrm{mM} \mathrm{NaCl}$, $\mathrm{pH} 7.5$ and $0.1 \%$ Tween-20) for $1 \mathrm{~h}$ at room temperature. Then, the membranes were incubated overnight at $4{ }^{\circ} \mathrm{C}$ with the primary antibodies. The membranes were washed once for 10 min with $4 \mathrm{X}$ TBS-T buffer and incubated for $1 \mathrm{~h}$ with horseradish peroxidase-conjugated anti-rabbit or anti-mouse immunoglobin (Santa Cruz Biotechnology Inc., Santa Cruz, $\mathrm{CA})$. The membranes were washed again for $10 \mathrm{~min}$ with $1 \mathrm{X}$ TBS-T buffer. Antigen-antibody complexes were detected by the enhanced chemiluminescence (ECL) detection system (GE Healthcare Biosciences, Pittsburgh, PA).

Cell motility assay. HCT116 cells were grown to confluence on $35-\mathrm{mm}$ cell culture dishes at $90 \%$ confluence, wounded with a 200- $\mu 1$ pipette tip, and marked at the injury line. After washing with phosphate-buffered saline (PBS), serum-free media (to prevent cell proliferation) containing either vehicle (DMSO) or various concentrations of baicalein was added for the indicated times. Wound closure of cells was observed and photographed under the microscope at x50 magnification.

In vitro migration assay. The migration capacity of HCT116 cells was determined using a modified 24-well Boyden 
chamber ( $8-\mu \mathrm{m}$-pore size) (Corning, Tewksbury, MA). The cells were seeded at a density of $6 \times 10^{4}$ cells in $100 \mu \mathrm{l}$ serumfree medium to the upper compartment of the Transwell and incubated in lower chamber containing either DMSO or baicalein for $24 \mathrm{~h}$ at $37^{\circ} \mathrm{C}$ in $5 \% \mathrm{CO}_{2}$. Cells that did not penetrate the filter were completely wiped off with cotton swabs, and cells that had migrated to the lower surface of the filter were fixed with methanol. The cells were then stained with methylene blue and eosin and observed under a phase contrast microscope and photographed at x50 magnification.

Gelatin zymographic analysis of secreted MMPs. Following incubation with baicalein, cell culture supernatants were collected and centrifuged at $400 \mathrm{x} \mathrm{g}$ for $5 \mathrm{~min}$. Cell-free supernatant was mixed with $2 \mathrm{X}$ sample buffer (Invitrogen, Carlsbad, CA) and zymography was performed using precast gels (10\% polyacrylamide and $0.1 \%$ gelatin). Following electrophoresis, gels were washed twice at room temperature for $30 \mathrm{~min}$ in $2.5 \%$ Triton $\mathrm{X}-100$, and subsequently washed in buffer containing $50 \mathrm{mM}$ Tris- $\mathrm{HCl}, 150 \mathrm{mM} \mathrm{NaCl}, 5 \mathrm{mM}$ $\mathrm{CaCl}_{2}, 1 \mu \mathrm{M} \mathrm{ZnCl}_{2}$, and $0.02 \% \mathrm{NaN}_{3}$ at $\mathrm{pH} 7.5$, and incubated in this buffer at $37^{\circ} \mathrm{C}$ for $24 \mathrm{~h}$. Thereafter, gels were stained with $0.5 \%$ (w/v) Coomassie brilliant Blue G-250 (Bio-Rad, Hercules, CA) for $1 \mathrm{~h}$, then lightly destained in methanol:acetic acid:water (3:1:6). Clear bands appeared on the Coomassie stained Blue background in the areas of gelatinolytic activity. Gels were scanned and images were processed for extraction of the blue channel signal, which converted it to black and white.

Animal study. The animal protocol used in this study was reviewed by the Pusan National University-Institutional Animal Care and Use Committee (PNU-IACUC, Busan, Korea) on the ethics of animal procedures and scientific care, were approved. Five-week-old male ICR mice were purchased from Samtako Co., Ltd. (Osan, Korea). All animals were housed in plastic cages (4 mice/cage) and had free access to drinking water and a basal diet (Formula M07; Feed lab) under controlled conditions of humidity (50 $\pm 10 \%)$, light $(12 / 12 \mathrm{~h}$ light/dark cycle), and temperature $\left(\sim 23^{\circ} \mathrm{C}\right)$. After arrival, the animals were quarantined for the first 7 days, and then randomized by body weights into experimental and control groups. A colonic carcinogen AOM was purchased from Sigma-Aldrich. DSS with a molecular weight of 36,000-50,000 (cat. no. 160110) was purchased from MP Biomedicals, LLC (Aurora, OH). For the induction of colitis, DSS was dissolved in water at a concentration of $1.5 \%(\mathrm{w} / \mathrm{v})$. Experimental groups included group 1 (control group, $\mathrm{n}=6)$; group $2(\mathrm{n}=8)$ was treated with AOM and DSS; groups $3-5$ ( $n=8$ for each group) were treated with AOM, DSS and baicalein $(1 \mathrm{mg} / \mathrm{kg}$ for group $3,5 \mathrm{mg} / \mathrm{kg}$ for group 4 , $10 \mathrm{mg} / \mathrm{kg}$ for group 5). Mice in groups 2-5 were given a single intraperitoneal injection of AOM $(10 \mathrm{mg} / \mathrm{kg}$ body weight). Starting 1 week after the injection, animals received $1.5 \%$ DSS in the drinking water for 7 days. Subsequently, groups $3-5$ received the diets containing 1,5 and $10 \mathrm{mg} / \mathrm{kg}$ baicalein for 16 weeks, respectively. All animals were sacrificed at week 16 after administration of baicalein. At sacrifice, complete necropsies were done on all mice. Histopathological examination was performed on paraffin-embedded sections after hematoxylin and eosin (H\&E) staining.

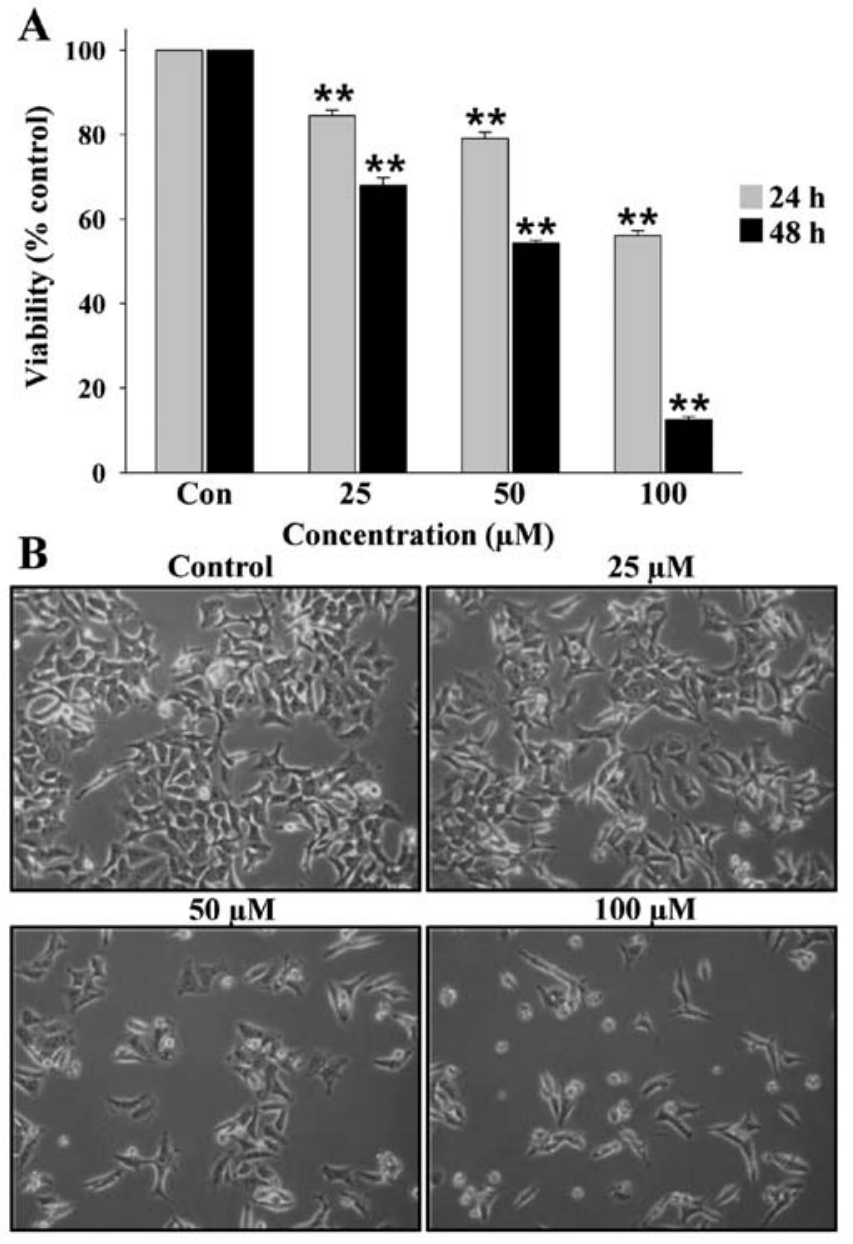

Figure 2. Effect of baicalein on viability of HCT116 cells. (A) The cells were treated with different concentrations of baicalein for 24 and $48 \mathrm{~h}$, and then percentage of cell survival was determined using the MTT assay. Results are expressed as mean $\pm \mathrm{SD}(\mathrm{n}=6)$. ${ }^{* * *} \mathrm{p}<0.01$ compared control cells. Con, control. (B) HCT116 cells were treated for $24 \mathrm{~h}$ with the indicated concentrations of baicalein and morphological changes were observed by phase contrast microscopy at x320 magnification.

Statistical analysis. Results are expressed as the mean \pm SD of three separate experiments and analyzed by Student's t-test. Means were considered significantly different at ${ }^{*} \mathrm{p}<0.05$ or ${ }^{* *} \mathrm{p}<0.01$.

\section{Results}

Baicalein reduces the viability of HCT116 cells. To investigate the effects of baicalein on the viability of HCT116 cells, the MTT assay was performed. As shown in Fig. 2A, cell viability was significantly decreased by treatment of baicalein in a concentration-dependent manner. The concentrations required for half-maximal inhibition $\left(\mathrm{IC}_{50}\right)$ of the cells were about $100 \mu \mathrm{M}$ for HCT116 cells after $24 \mathrm{~h}$ and about $50 \mu \mathrm{M}$ after $48 \mathrm{~h}$. Treatment with baicalein for $24 \mathrm{~h}$ showed distinct morphological changes compared with control (Fig. 2B). They were rounded and more dispersed with aggregation in a concentration-dependent manner.

Baicalein induces apoptosis in HCT116 cells. To investigate whether the growth inhibitory effects of baicalein were due 

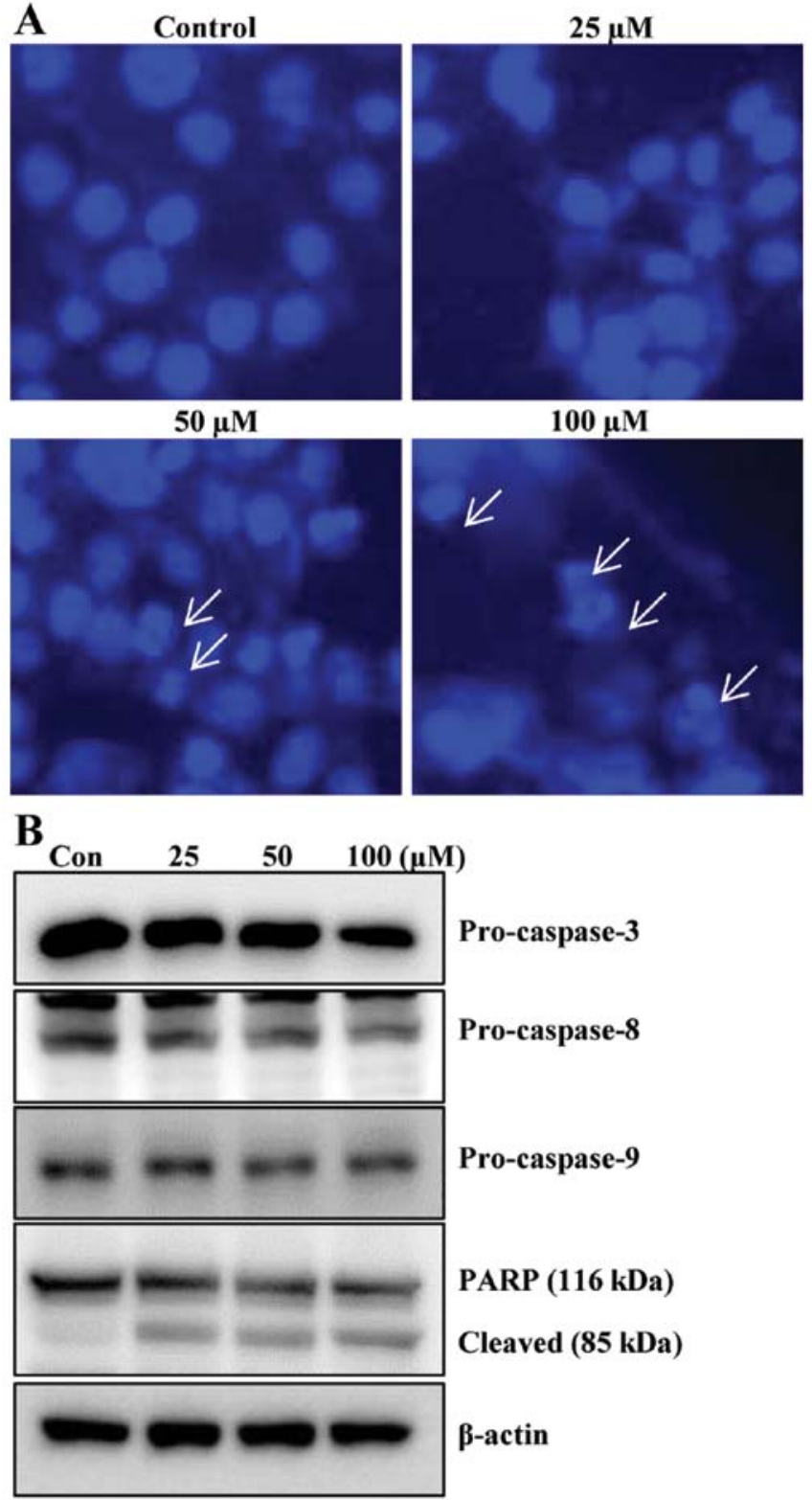

Figure 3. Induction of apoptosis in HCT116 cells by baicalein. (A) The cells were treated with baicalein for $24 \mathrm{~h}$, then stained nuclei with fluorescent DNA-binding dye, Hoechst 33342, and then photographed with a fluorescent microscope using a blue filter at x320 magnification. Arrows, apoptotic cells. (B) HCT116 cells were treated with indicated concentrations of baicalein for $24 \mathrm{~h}$, collected, lysed and then cellular proteins were separated and immunoblotted. The membranes were probed with pro-caspase-3, pro-caspase-8, pro-caspase-9, PARP (116 kDa), and cleaved PARP ( $85 \mathrm{kDa})$ Proteins were visualized using the ECL detection system. Representative results from three independent experiments are shown. Actin was used as a loading control. Con, control.

to the induction of apoptosis in HCT116 cells, morphological changes of cellular structures were assessed with Hoechst 33342 staining. As shown in Fig. 3A, nuclei with chromatin condensation and formation of apoptotic bodies, which are characteristics of apoptosis, were seen in cells cultured with baicalein in a concentration-dependent manner, whereas the control cells maintained their nuclear structure intact. During apoptotic process, caspases play major roles in both the intrinsic and extrinsic pathways. Thus, the levels of caspase- $3,-8$ and -9

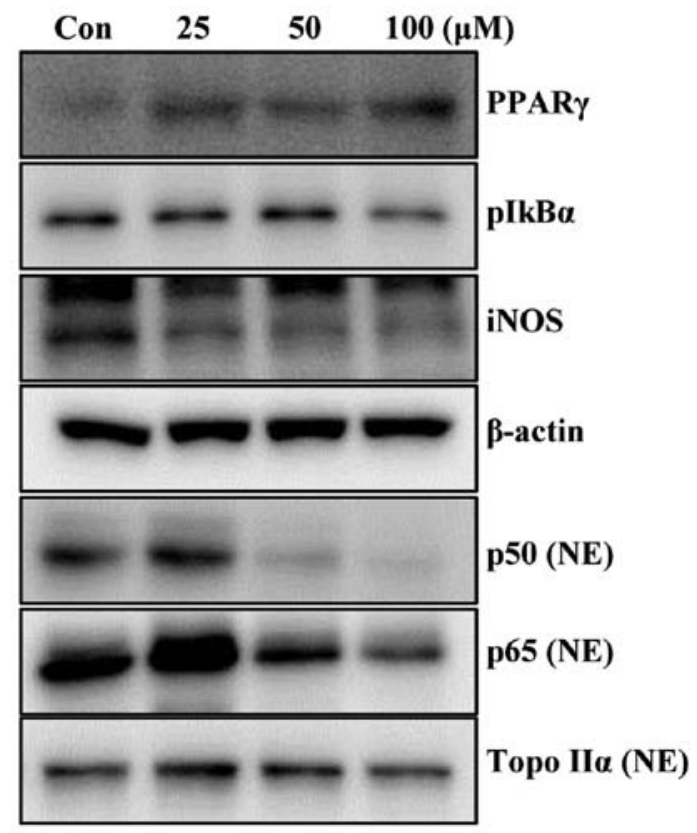

Figure 4. Anti-inflammatory effect of baicalein by inhibiting NF- $\kappa \mathrm{B}$ expression through induction of PPAR $\gamma$ activation in HCT116 cells. The cells were treated with baicalein for $24 \mathrm{~h}$, and then western blot analysis was performed to detect PPAR $\gamma, \mathrm{pI} \kappa \mathrm{B} \alpha$, iNOS, p50 and p65 in HCT116 cells. Topo II $\alpha$ and $\beta$-actin were detected as positive controls. One representative blot for each protein is shown from three independent experiments that yielded similar results. Con, control.

were investigated in order to determine whether caspases are associated with baicalein-induced apoptosis in HCT116 cells. Treatment with baicalein showed decreased pro-caspase- 3 and -8 levels and induced cleavage of PARP (Fig. 3B). These results indicated that growth inhibitory effects of baicalein were due to the induction of apoptosis in HCT116 cells.

Baicalein suppresses the $N F-\kappa B$ activity through the PPAR activation. PPAR $\gamma$ agonists can inhibit the activities of signal dependent transcription factors, such as NF- $\kappa \mathrm{B}$. This function could contribute to the anti-inflammatory actions of PPAR $\gamma$. To verify whether baicalein modulates the NF- $\kappa \mathrm{B}$ activity through the PPAR $\gamma$ activation, western blot analysis was performed and expression levels measured of NF- $\kappa \mathrm{B}$-related protein. Treatment of baicalein induced PPAR $\gamma$ activation and inhibited $\mathrm{pI \kappa \textrm {B } \alpha}, \mathrm{p} 50, \mathrm{p} 65$ and iNOS levels (Fig. 4). These results suggested that NF- $\kappa \mathrm{B}$ activity was suppressed through PPAR $\gamma$ activation by baicalein treatment in HCT116 cells.

Baicalein suppresses migration. To determine whether or not biacalein inhibits migration of HCT116 cells, wound-healing experiments were performed. Results demonstrated that $50 \mu \mathrm{M}$ of baicalein for $24 \mathrm{~h}$, which was not cytotoxic, as shown by the MTT assay, delayed the migration of HCT116 cells compared to that of control cells (Fig. 5A). Using a Boyden chamber migration assay, we next examined the question of which baicalein decreases the activity of cell migration. As shown in Fig. 5B, treatment of cells with $50 \mu \mathrm{M}$ of baicalein markedly reduced cell invasion through the Matrigel chamber. Because cell migration plays an important role in the metastasis process, and 

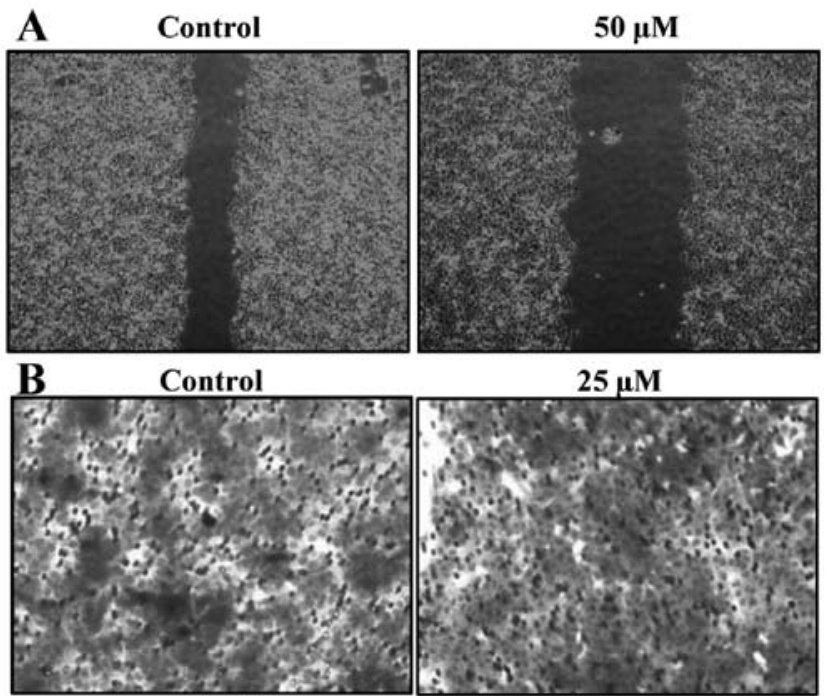

$50 \mu \mathrm{M}$
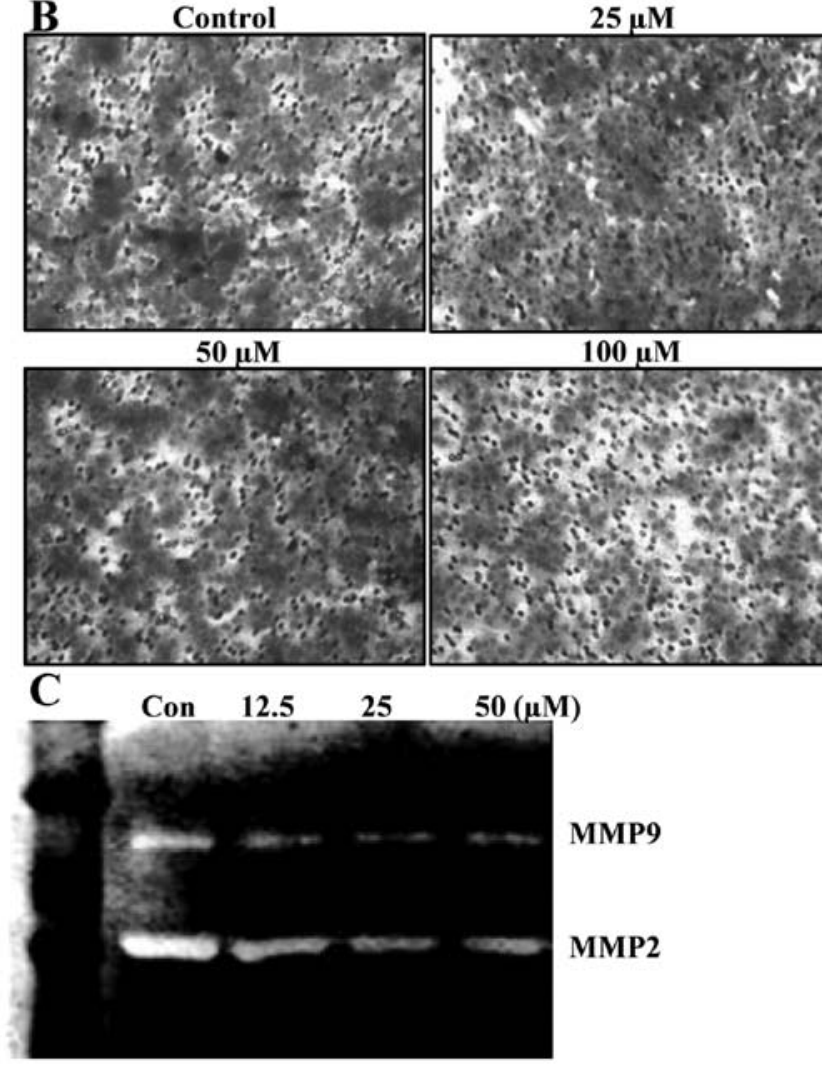

Figure 5. Inhibition of migration by baicalein in HCT116 cells. (A) Cells were grown to confluence on $35 \mathrm{~mm}$ cell culture dishes; a scratch was then made through the cell layer using a pipette tip. After washing with PBS, serum-free media (to prevent cell proliferation), containing either vehicle or baicalein, was added for $24 \mathrm{~h}$. Photographs were taken for evaluation of cell movement into the wounded area. (B) For the migration assay, cells pre-incubated with various concentrations of baicalein were plated onto the upper wells of the chamber. FBS (10\%) was added to the lower wells for $24 \mathrm{~h}$ to induce cell migration. After $24 \mathrm{~h}$, cells on the bottom side of the filter were fixed, stained and counted. Migration was assessed by counting migrated cells in five microscopic fields per well at x320 magnification (C) After incubation with baicalein for $24 \mathrm{~h}$, medium was collected, and the activity of MMP-2 and -9 was measured by zymography. Con, control.

migration of the basement membrane is primarily mediated by gelatinase matrix metalloproteinases (MMPs), we tested the effects of baicalein on MMP gelatin zymography. Treatment of baicalein reduced the expression of the MMP-2 and -9 activities (Fig. 5C). These results suggested that the anti-migration effect of baicalein is associated with inhibition of MMP-2 and -9 activities in HCT116 cells.

Baicalein inhibits AOM/DSS-induced colitis and tumorigenesis. The AOM/DSS model is a widely used inflammation-associated colon cancer model in rodents. The antitumor activity of dietary administration of baicalein on AOM/DSS-induced tumorigenesis was evaluated. The study protocol is summarized in Fig. 6A. During the experiments, feeding the mice with the three different doses of baicalein-containing diets did not produce any observable clinical toxicity or significant changes in body weight compared to control (Fig. 6B). But colon length was recovered by administration of baicalein in a dose-dependent manner compared to the control (Fig. 6D). Macroscopically, colonic tumors developed in the mice of groups 2 through 5 with different incidence rate and multiplicity (Fig. 6C and E). Group 2 (AOM/DSS group) had mainly adenocarcinoma (ADC, Fig. 6F) with a multiplicity of 2.67 \pm 1.03 . The incidence of ADC in groups 3-5 was less than that of group 2 and the multiplicity of ADC in groups $3-5$ is $1.63 \pm 0.69,1.25 \pm 0.24$ and $0.88 \pm 0.41$, respectively. The multiplicity of colonic ADC in groups 4 and 5 was significantly smaller than group 2 ( $\mathrm{p}<0.01$ ) (Fig. 6E). In H\&E staining, group 2 (AOM/DSS group) animals showed increased tissue inflammation, but administration of baicalein reduced tissue inflammation compared to control dose-dependently (Fig. 6F).

\section{Discussion}

In this study, we found concentration-dependent cell growth inhibition in response to baicalein in HCT116 cells, in accordance with previous research in bladder cancer (16). Cell growth was maximally inhibited by the treatment of $100 \mu \mathrm{M}$ baicalein. The concentrations of $50 \%$ inhibition of tumor proliferation range between 20 and $200 \mu \mathrm{M}$, depending on the type of tumor cells tested.

Baicalein is a natural plant flavone originally isolated from the roots of Scutellaria baicalensis. This compound exhibits various biological effects, including anti-inflammatory (17) and antitumor activity (18). Although Scutellaria has been shown to have almost no or very low toxicity to animals and humans (The grand dictionary of Chinese herbs, 1977). So far, baicalein, at doses that are toxic to malignant cells have been shown to have no or very little toxicity to normal myeloid cells (19) and also no effect on the viability of normal human prostate epithelial cells (20). In contrast, baicalein has been shown to inhibit growth of various human cancer cell lines $(21,22)$. Baicalein also possesses a direct cytotoxicity to a large panel of human malignant cell lines by inducing apoptotic cell death. Oral administration of $20 \mathrm{mg} / \mathrm{kg}$ baicalein was also shown to inhibit growth of established prostate tumors by approximately $55 \%$ (23). These data demonstrate that baicalein has therapeutic potential against cancers.

Apoptosis is an important process required for homeostasis. Apoptosis occurs through two broad pathways: the intrinsic pathway and extrinsic pathway (24). To clarify whether the effect on cell growth inhibition was due to apoptosis in colon cancer cells, we performed morphological experiments and western blot analysis after treatment of baicalein for $24 \mathrm{~h}$. Treatment with baicalein decreased the expression levels of pro-caspase- 3 and -8 , and induced cleavage of PARP. Thus, it involved the extrinsic pathway to induce apoptosis.

The PPAR $\gamma$ agonists affect cell proliferation, differentiation, and apoptosis in a PPAR $\gamma$-dependent and/or -independent manner, and thereby represent a potentially important family of therapeutic compounds for cancer treatment. Many studies 
A
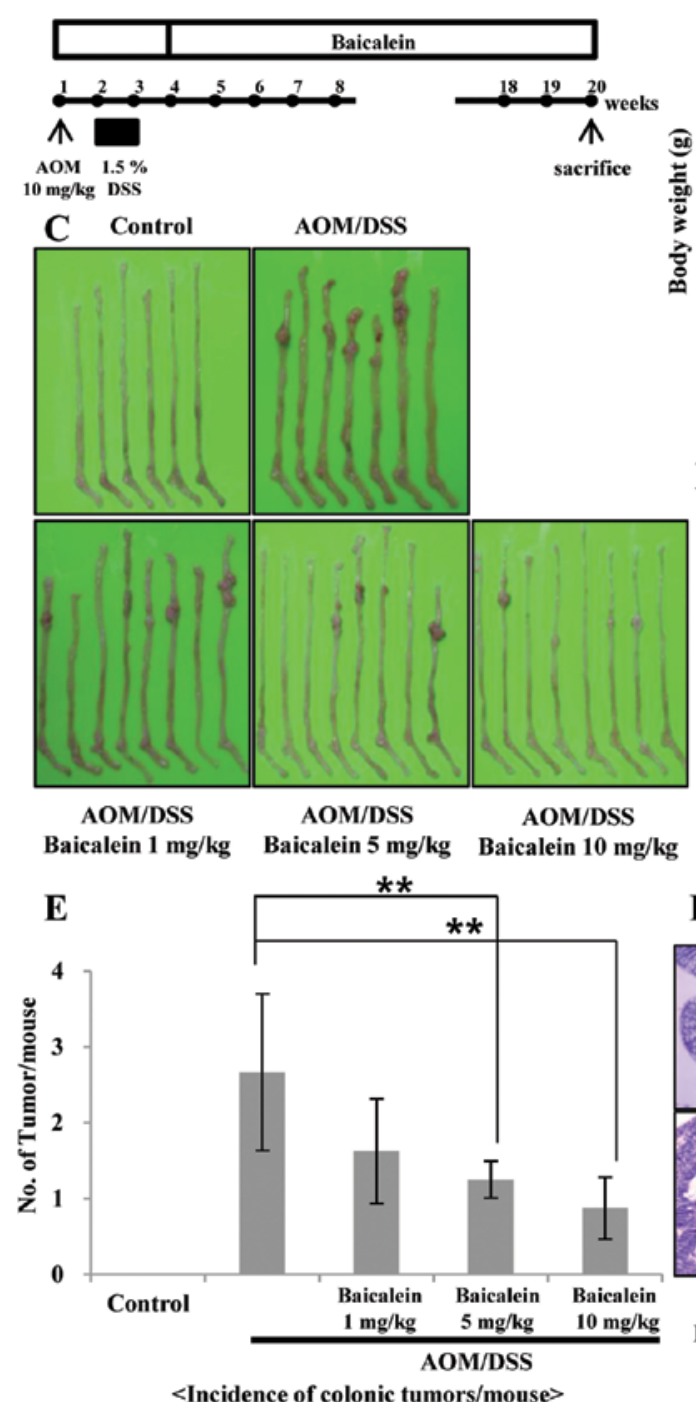

\section{B}

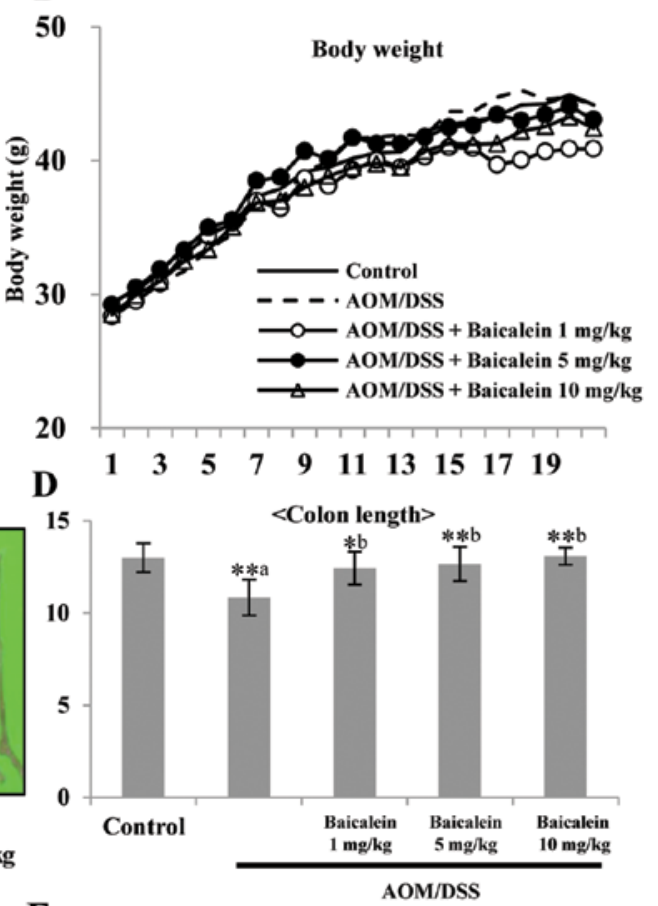

F Control AOM/DSS

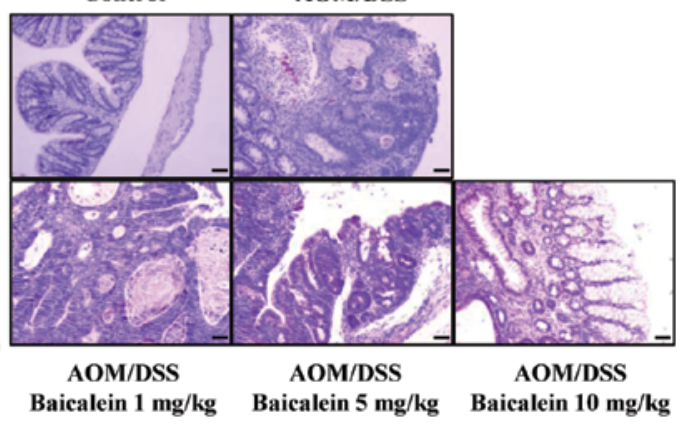

Figure 6. Administration of baicalein inhibited inflammation-induced tumors. (A) Total experimental protocols. (B) Body weight changes in mice. (C) Representative macroscopic views of the colons of mice. (D) The length of the large bowel in mice. ${ }^{\mathrm{a}} \mathrm{p}<0.05$ versus the control. ${ }^{* \mathrm{~b}} \mathrm{p}<0.05,{ }^{* * \mathrm{~b}} \mathrm{p}<0.01$ versus the AOM/DSS treatment. (E) Incidence of inflammation-induced colon cancer. ${ }^{* *} \mathrm{p}<0.01$ compared with the AOM/DSS treatment. (F) Representative histopathological images of control colon (group 1), colonic proliferation lesions that developed in mice that received AOM/DSS (group 2) and AOM/DSS with different concentration of baicalein (groups 3-5). H\&E stain. Bar, $50 \mu \mathrm{m}$.

show that PPAR $\gamma$ agonists such as thiazolidinedione have anti-tumorigenic properties in colorectal cancer by increasing the expression of tumor suppressor genes (25). Activation of PPAR $\gamma$ results in anti-inflammatory effects in several cell types, including smooth muscle cells, endothelial cells. PPARs act as anti-inflammatory agents by interfering with the transcriptional pathways involved in inflammatory responses, such as the modulation of $N F-\kappa B$ signaling. NF- $\kappa \mathrm{B}$ is the key transcriptional factor for synthesis of pro-inflammatory mediators, including iNOS, COX-2 and TNF- $\alpha$. NF- $\kappa \mathrm{B}$ also plays central roles in carcinogenesis and inflammation, and thus it is one of the molecular targets of cancer chemoprevention and therapy (26). $\mathrm{NF}-\kappa \mathrm{B}$ activation is reported to be involved in colon carcinogenesis and certain NF- $\mathrm{B}$ inhibitors are able to suppress cancer development in these tissues (27). Treatment of HCT116 cells with baicalein resulted in increase in the expression of PPAR $\gamma$ in a concentration-dependent manner and baicalein inhibited p50, p65 and iNOS levels concentration-dependently. Baicalein not only directly affects $N F-\kappa B$ transcription factors but also affects invasion and migration signaling molecules such as MMP-2 and MMP-9 (28). Treatment with baicalein inhibited cell migration through inhibiting, respectively, MMP-2, MMP-9 expression concentration-dependently as detected by gelatin zymography assay. Therefore, baicalein have effective anti-metastatic activity for the treatment of colon cancer by inhibiting the expression of MMP-9 and MMP-2, thus blocking cell migration and invasion pathways. Baicalein is a potent PPAR $\gamma$ activator that inhibits NF- $\kappa \mathrm{B}$ and mediates inflammatory responses in colon cancer cells.

Accumulative evidence has shown a significant association between deficiency of PPAR $\gamma$ and IBD (29). In addition, activation of PPAR $\gamma$ attenuated the inflammation in the gut (30). These results suggested that colonic PPAR $\gamma$ may be a promising therapeutic target in patients suffering from IBD. In this study 
chemopreventive ability of baicalein at 3 different dose levels $(1,5,10 \mathrm{mg} / \mathrm{kg}$ in diet) using inflammation-induced colon carcinogenesis model in mice were assessed. All doses of baicalein suppressed colonic inflammation and reduced the tumor incidence induced by AOM/DSS in a dose-dependent manner.

In conclusion, our findings indicate that the flavone, baicalein, being a major constituent of the Scutellaria baicalensis Georgi is one of the good candidates with multiple targets for cancer chemoprevention in colon related to inflammation associated-carcinogenesis.

\section{Acknowledgements}

This study was supported by National Research Foundation of Korea (NRF) grant funded by the Korea government (MOST) (no. 20120009374). We thank Aging Tissue Bank for providing research information.

\section{References}

1. Tenesa A and Dunlop MG: New insights into the aetiology of colorectal cancer from genome-wide association studies. Nat Rev Genet 10: 353-358, 2009.

2. Rubin DC, Shaker A and Levin MS: Chronic intestinal inflammation: inflammatory bowel disease and colitis-associated colon cancer. Front Immunol 3: 107, 2012.

3. Loftus EV Jr: Clinical epidemiology of inflammatory bowel disease: Incidence, prevalence, and environmental influences. Gastroenterology 126: 1504-1517, 2004.

4. Kim ES and Kim WH: Inflammatory bowel disease in Korea: epidemiological, genomic, clinical, and therapeutic characteristics. Gut Liver 4: 1-14, 2010.

5. Asakura K, Nishiwaki Y, Inoue N, Hibi T, Watanabe M and Takebayashi T: Prevalence of ulcerative colitis and Crohn's disease in Japan. J Gastroenterol 44: 659-665, 2009.

6. Dubuquoy L, Rousseaux C, Thuru X, et al: PPARgamma as a new therapeutic target in inflammatory bowel diseases. Gut 55 1341-1349, 2006.

7. Bassaganya-Riera J, Reynolds K, Martino-Catt S, et al: Activation of PPAR gamma and delta by conjugated linoleic acid mediates protection from experimental inflammatory bowel disease. Gastroenterology 127: 777-791, 2004.

8. Liang HL and Ouyang Q: A clinical trial of rosiglitazone and 5 -aminosalicylate combination for ulcerative colitis. Zhonghua Nei Ke Za Zhi 45: 548-551, 2006 (In Chinese).

9. Bassaganya-Riera J, DiGuardo M, Climent M, et al: Activation of PPARgamma and delta by dietary punicic acid ameliorates intestinal inflammation in mice. Br J Nutr 106: 878-886, 2011.

10. Ricote $M$ and Glass CK: PPARs and molecular mechanisms of transrepression. Biochim Biophys Acta 1771: 926-935, 2007.

11. Li-Weber M: New therapeutic aspects of flavones: the anticancer properties of Scutellaria and its main active constituents Wogonin, Baicalein and Baicalin. Cancer Treat Rev 35: 57-68, 2009.

12. Peng CY, Pan SL, Huang YW, Guh JH, Chang YL and Teng CM: Baicalein attenuates intimal hyperplasia after rat carotid balloon injury through arresting cell-cycle progression and inhibiting ERK, Akt, and NF-kappaB activity in vascular smooth-muscle cells. Naunyn Schmiedebergs Arch Pharmacol 378: 579-588, 2008.

13. Lee EK, Kim JM, Choi J, et al: Modulation of NF-kappaB and FOXOs by baicalein attenuates the radiation-induced inflammatory process in mouse kidney. Free Radic Res 45: 507-517, 2011.
14. Lea MA, Ibeh C, Deutsch JK, Hamid I and desBordes C: Inhibition of growth and induction of alkaline phosphatase in colon cancer cells by flavonols and flavonol glycosides. Anticancer Res 30: 3629-3635, 2010.

15. Pidgeon GP, Kandouz M, Meram A and Honn KV: Mechanisms controlling cell cycle arrest and induction of apoptosis after 12-lipoxygenase inhibition in prostate cancer cells. Cancer Res 62: 2721-2727, 2002.

16. Chao JI, Su WC and Liu HF: Baicalein induces cancer cell death and proliferation retardation by the inhibition of CDC2 kinase and survivin associated with opposite role of $\mathrm{p} 38$ mitogen-activated protein kinase and AKT. Mol Cancer Ther 6: 3039-3048, 2007.

17. Hsieh CJ, Hall K, Ha T, Li C, Krishnaswamy G and Chi DS: Baicalein inhibits IL-1beta- and TNF-alpha-induced inflammatory cytokine production from human mast cells via regulation of the NF-kappaB pathway. Clin Mol Allergy 5: 5, 2007.

18. Takahashi H, Chen MC, Pham H, et al: Baicalein, a component of Scutellaria baicalensis, induces apoptosis by Mcl-1 downregulation in human pancreatic cancer cells. Biochim Biophys Acta 1813: 1465-1474, 2011.

19. Ma Z, Otsuyama K, Liu S, et al: Baicalein, a component of Scutellaria radix from Huang-Lian-Jie-Du-Tang (HLJDT), leads to suppression of proliferation and induction of apoptosis in human myeloma cells. Blood 105: 3312-3318, 2005.

20. Lee DH, Kim C, Zhang L and Lee YJ: Role of p53, PUMA, and Bax in wogonin-induced apoptosis in human cancer cells. Biochem Pharmacol 75: 2020-2033, 2008.

21. Zhang HB, Lu P, Guo QY, Zhang ZH and Meng XY: Baicalein induces apoptosis in esophageal squamous cell carcinoma cells through modulation of the PI3K/Akt pathway. Oncol Lett 5: 722-728, 2013.

22. Zhang Y, Song L, Cai L, Wei R, Hu H and Jin W: Effects of baicalein on apoptosis, cell cycle arrest, migration and invasion of osteosarcoma cells. Food Chem Toxicol 53: 325-333, 2013

23. Bonham M, Posakony J, Coleman I, Montgomery B, Simon J and Nelson PS: Characterization of chemical constituents in Scutellaria baicalensis with antiandrogenic and growthinhibitory activities toward prostate carcinoma. Clin Cancer Res 11: 3905-3914, 2005.

24. Lorenzo HK and Susin SA: Therapeutic potential of AIF-mediated caspase-independent programmed cell death. Drug Resist Updat 10: 235-255, 2007.

25. Yamaguchi K, Cekanova M, McEntee MF, et al: Peroxisome proliferator-activated receptor ligand MCC-555 suppresses intestinal polyps in ApcMin/+ mice via extracellular signalregulated kinase and peroxisome proliferator-activated receptor-dependent pathways. Mol Cancer Ther 7: 2779-2787, 2008.

26. Surh YJ: NF-kappa B and Nrf2 as potential chemopreventive targets of some anti-inflammatory and antioxidative phytonutrients with anti-inflammatory and antioxidative activities. Asia Pac J Clin Nutr 17 (Suppl 1): 269-272, 2008.

27. Rajakangas J, Misikangas M, Paivarinta E and Mutanen M: Chemoprevention by white currant is mediated by the reduction of nuclear beta-catenin and NF-kappaB levels in Min mice adenomas. Eur J Nutr 47: 115-122, 2008.

28. Chiu YW, Lin TH, Huang WS, et al: Baicalein inhibits the migration and invasive properties of human hepatoma cells. Toxicol Appl Pharmacol 255: 316-326, 2011.

29. Aoyagi Y, Nagata S, Kudo T, et al: Peroxisome proliferatoractivated receptor gamma 2 mutation may cause a subset of ulcerative colitis. Pediatr Int 52: 729-734, 2010.

30. Yamamoto-Furusho JK, Penaloza-Coronel A, SanchezMunoz F, Barreto-Zuniga R and Dominguez-Lopez A: Peroxisome proliferator-activated receptor-gamma (PPARgamma) expression is downregulated in patients with active ulcerative colitis. Inflamm Bowel Dis 17: 680-681, 2011. 